\title{
Transverse colon cancer presenting as acute abdominal wall abscess
}

\author{
Khalil ElGendy, ${ }^{1}$ Mohammed Al Duhileb, ${ }^{2}$ Amro Salem ${ }^{1}$
}

${ }^{1}$ Department of Colorectal Surgery, King Fahad Specialist Hospital, Dammam, Saudi Arabia

${ }^{2}$ Department of Surgery, King Fahad Specialist Hospital, Dammam, Saudi Arabia

\section{Correspondence to} Mr Khalii ElGendy, k.m.elgendy@gmail.com

Accepted 8 April 2014

\section{DESCRIPTION}

A 54-year-old woman presented with an acute painful swelling in the upper abdomen. The patient is a smoker, diabetic and had history of chronic constipation. The swelling was acute with 3 days

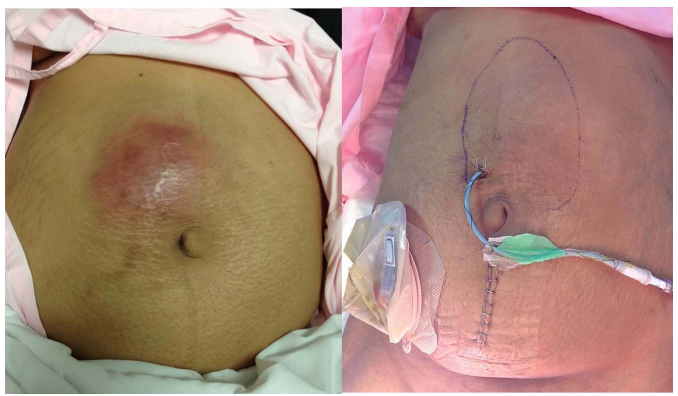

Figure 1 On the left: the patient presenting with acute abdominal wall swelling with abdominal distention. On the right: the patient underwent pigtail insertion to drain the abscess and diverting loop ileostomy where distention was relieved. duration and was associated with mild fever. On examination, there was an acute tender hot swelling in the epigastric region with abdominal distention (figure 1). Ultrasound was carried out and revealed a large heterogeneous fluid collection, and large pelvic cyst requiring CT for further assessment (figure 2). The CT scan was carried out revealing a mid-transverse colonic mass invading the anterior abdominal with connection to subcutaneous abscess $(4 \times 10 \mathrm{~cm})$, and causing further dilation of the transverse colon. There was also an incidental adenexal cyst with no evidence of distant metastasis (figure 3).

The patient was offered drainage of the abscess with pigtail catheter attached. Colonoscopy was performed confirming the colonic mass where multiple biopsies were taken. Trial of stenting failed with inability to pass the guidewire through the lumen and arrest of the water soluble 'Gastrografin' contrast at the mass (figure 4). During this course, the patient developed absolute constipation and marked distention. The patient underwent diverting loop ileostomy to relieve the obstruction (figure 1).

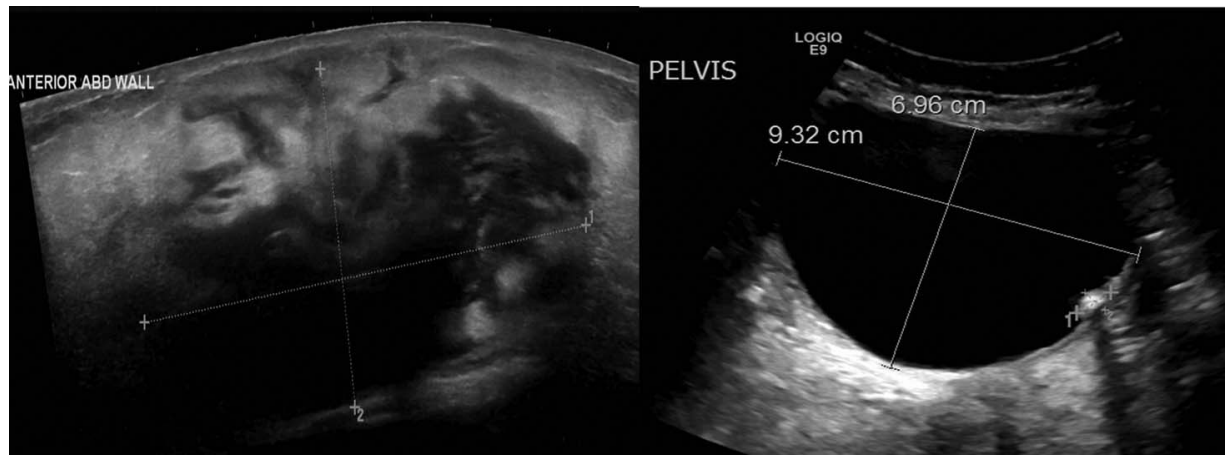

Figure 2 Ultrasound images revealing the anterior abdominal wall collection and the pelvic cyst.

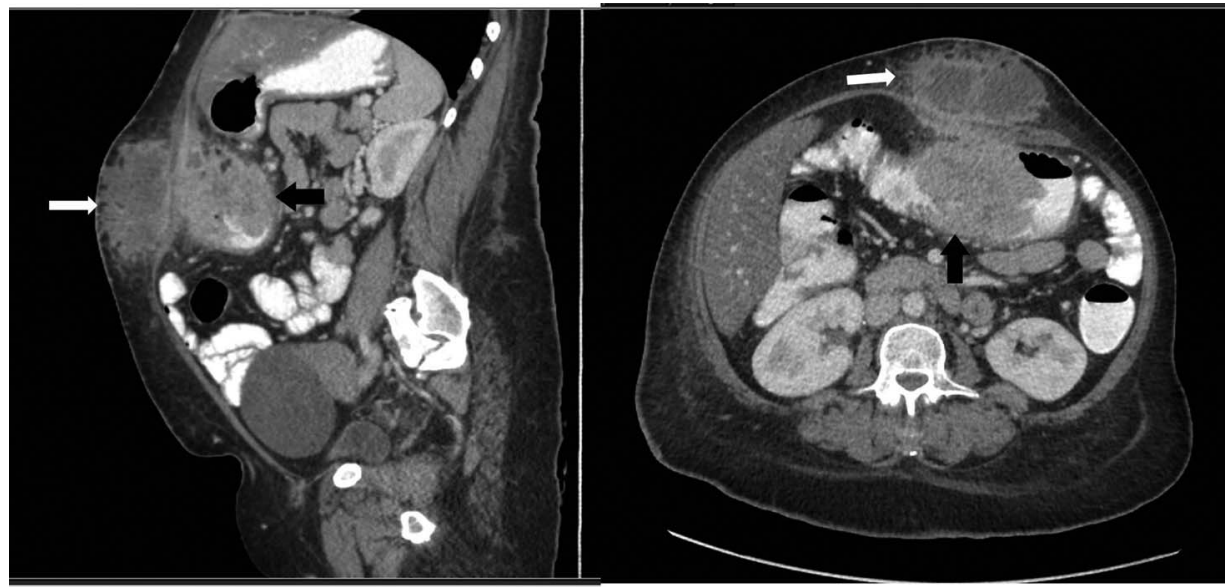

To cite: ElGendy K, Al Duhileb M, Salem A. BMJ Case Rep Published online: [please include Day Month Year] doi:10.1136/bcr-2014204105
CrossMark

Figure 3 CT scan showing the transverse colon mass (black arrow) infiltrating abdominal wall with connection to the abscess (white arrow). Note the incidental adenexal cyst in the pelvis (sagittal section). 


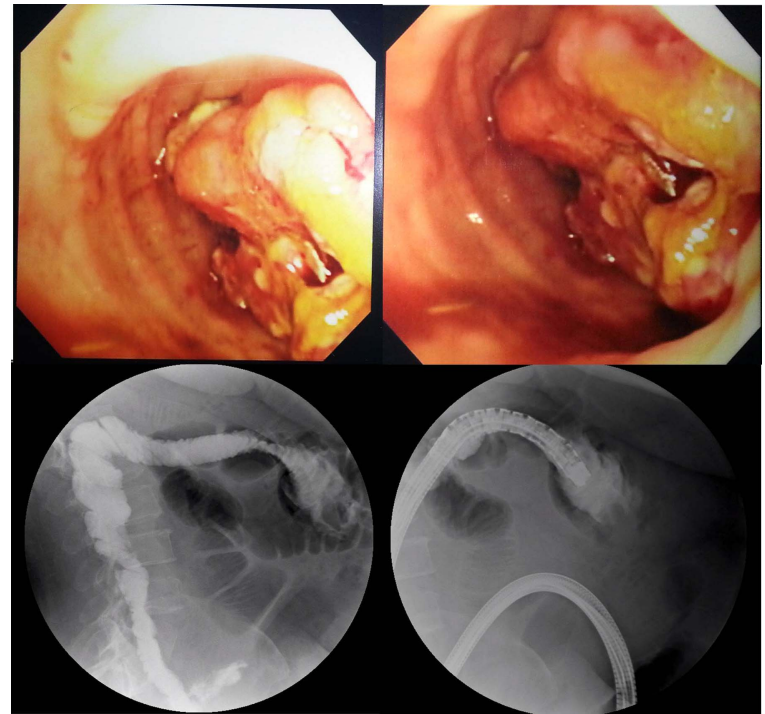

Figure 4 Colonoscopic imaging of the obstructing colonic mass, with $X$-rays showing inability of the scope to pass through the mass (below right) and arrest of the contrast at the site of the mass.

The colonoscopic biopsy confirmed the diagnosis of moderately differentiated adenocarcinoma. Extended right hemicolectomy with complete en bloc resection of the abdominal wall with abdominal wall reconstruction using component separation



Figure 5 Surgical specimen, white arrows pointing to the proximal (ileum) margin (with resection of the early stoma, empty white arrow) and distal (colon) margins (solid white arrow), while black arrows pointing to the anterior abdominal wall. Notice the skin staplers of earlier exploration, where the earlier incision was included in the anterior abdominal wall en bloc excision (empty black arrow). technique without the mesh use. Resection of the small bowel with the stoma was done with single ileocolic anastomosis (figure 5). Removal of the ovarian cyst was done revealing benign serous cystadenoma. The pathological staging (pT4b, $\mathrm{N} 0, \mathrm{Mx}$ ) with uninvolved 34 lymph nodes retrieved. All surgical margins were not involved. There was also no lymphovascular or perineural invasion. The final stage was Duke B or Stage IIC according to American Joint Committee on Cancer (AJCC) staging. According to National Comprehensive Cancer Network (NCCN) guidelines ${ }^{1}$ the patient can be offered adjuvant chemotherapy or observation. The patient refused chemotherapy and she will be going through appropriate surveillance programmes with regular clinical visits, CT scans and colonoscopies.

There were few cases reported about the presentation of colonic cancer as acute abdominal wall abscess. ${ }^{2} 3$ En bloc dissection should be offered to the patient which has its impact on the prognosis and quality of life of the patient. The involvement of abdominal wall itself by the colonic cancer with abscesses does not adversely affect the prognosis with even potential cure if the tumour is technically resectable and all surgical margins are clear. ${ }^{3}$ Such a case raises the importance of awareness of such rare presentation where high index of suspicion is needed and essential investigations should be carried out.

\section{Learning points}

Colonic cancers can rarely present with acute abdominal wall abscesses.

- The case raises the importance of such a fact which needs high index of suspicion with appropriate investigations to reach the diagnosis.

- En bloc resection of the colonic cancers with the abdominal wall should be offered as this has its impact on the prognosis and quality of life.

Contributors KE contributed towards idea generation, literature review, case scenarios, article writing and data collection. MA acquired informed consent, contributed towards data collection and photographing. AS managed the case and took care of final revision of the manuscript.

Competing interests None.

Patient consent Obtained.

Provenance and peer review Not commissioned; externally peer reviewed.

\section{REFERENCES}

1 NCCN clinical practice guidelines in oncology: Colon Cancer, version 1.2014. http:/ www.ncen.org/professionals/physician_gls/pdf/colon.pdf

2 Souei Mhiri M, Rouatbi I, Tlili Graies K, et al. Abdominal wall abscess as the presenting sign in carcinoma of the colon report of 4 cases. J Radiol 2005;86:1699-703.

3 El-Domeiri A, Whiteley HW Jr. Prognostic significance of abdominal wall involvement in carcinoma of cecum. Cancer 1970;26:552-6. 
Copyright 2014 BMJ Publishing Group. All rights reserved. For permission to reuse any of this content visit http://group.bmj.com/group/rights-licensing/permissions.

BMJ Case Report Fellows may re-use this article for personal use and teaching without any further permission.

Become a Fellow of BMJ Case Reports today and you can:

- Submit as many cases as you like

- Enjoy fast sympathetic peer review and rapid publication of accepted articles

- Access all the published articles

- Re-use any of the published material for personal use and teaching without further permission

For information on Institutional Fellowships contact consortiasales@bmjgroup.com

Visit casereports.bmj.com for more articles like this and to become a Fellow 